\title{
Da intenção à ação: relação histórica das tecnologias da informação e comunicação e o ensino da matemática
}

\author{
From Intention to Action: historical relation of information and communications \\ technology and math teaching
}

\author{
Josidalva de Almeida Batista (iD) https://orcid.org/0000-0002-8512-8016 \\ Universidade Federal do Sul e Sudeste do Pará \\ Josidalva.batista@unifesspa.edu.br
}

Alcicleide Pereira de Souza (iD https://orcid.org/0000-0001-8018-3035

Universidade Federal do Sul e Sudeste do Pará

alci.souza@unifesspa.edu.br

Narciso das Neves Soares (iD https://orcid.org/0000-0003-0331-4497

Universidade Federal do Sul e Sudeste do Pará

Narcisosoares52@unifesspa.edu.br

\section{Resumo}

Este artigo apresenta resultados de estudo sobre as Tecnologias de Informação e Comunicação (TIC) que podem conciliar uma finalidade secundária adicional, oportunizando ao usuário a construção de conhecimentos matemáticos. Em caráter qualitativo e de cunho bibliográfico e historiográfico, analisaram-se as fontes históricas produzidas e a possível associação entre as TIC e a aprendizagem incidental em Matemática. Do estudo, observou-se que as TIC estabelecem relações significativas com a construção de novos saberes e na medida em que se dialoga de forma crítica com tais tecnologias pode-se facilitar o ensino e a aprendizagem incidental de matemática.

Palavras-chave: Tecnologias de Informação e Comunicação. Aprendizagem. Ensino da Matemática.

\begin{abstract}
This paper reports study results about Information and Communications Technology (ICT), which reconcile an additional secondary finality, creating opportunities for users building mathematical background. In qualitative character and bibliographic and historiographic stamps, analyzed the historical sources produced and the possible association between ICT and incidental learning in Mathematics. In this study observed that ICT establishes significant relationships with the construction of new knowledge, and insofar as it critically dialogues with
\end{abstract}


such technologies, it can facilitate the teaching and incidental learning of mathematics.

Keywords: Information and Communications Technology. Learning. Math teaching.

\section{Introdução}

Quando um espectador vê na televisão, no celular ou no computador, um boletim sobre as pesquisas de intenção de voto, ele não imagina que tal atitude pode instigar novas aprendizagens em Matemática. Isso decorre devido à finalidade inicial da tecnologia ser a informação sobre a pesquisa eleitoral. Entretanto, como subproduto dessa ação, esse usuário pode sentir-se interessado em entender como aquela amostragem é capaz de representar o todo e, assim, tal anseio pode instigar o telespectador a construir novos saberes, como calcular médias e estabelecer percentagens encontradas no ensino do eixo Tratamento da Informação.

Nessa perspectiva, esse texto apresenta-se como uma investigação histórica de algumas tecnologias de informação e comunicação que podem conciliar uma finalidade secundária adicional, oportunizando ao usuário a construção de conhecimentos matemáticos. Parte-se do princípio de que as memórias das Tecnologias de Informação e Comunicação (TIC) podem auxiliar o leitor a compreender a possibilidade do desempenho de uma função adicional a sua finalidade precípua. Para tanto, buscou-se realizar um apanhado interdisciplinar entre a História, Comunicação, Matemática e Antropologia para se compreender tal processo.

As recentes pesquisas em Educação Matemática apontam caminhos no processo de aprendizagem apoiado nas novas TIC, assim, tornam-se pertinentes os registros dessa relação desde as primitivas representações até os tempos atuais. Nesse trabalho, compreendem-se as perspectivas de construção de conhecimentos matemáticos e os caminhos dessa interação no contexto brasileiro.

Esta pesquisa tem como fundamentação teórica as bases da Etnomatemática, buscando referências em autores como D’Ambrósio (2001; 2013), Gerdes (2010), Vergani (2007), dentre outros. Também se investiga a aprendizagem incidental sob a perspectiva de Antonello (2006; 2011), Luckesi (2011) e Marsick e Watkins (2001).

A pesquisa tem caráter de abordagem qualitativa e de cunho metodológico bibliográfica e historiográfico, analisando fontes históricas produzidas, buscando a análise da possível associação entre TIC e a aprendizagem em Matemática. Reforça-se que para fins de compreensão do leitor, utiliza-se os conhecimentos matemáticos formais como parâmetro para entendimento do saber produzido pelas sociedades, especialmente as mais primitivas. Entretanto, não se pretende reduzir o conhecimento desses povos, pelo contrário, entendendo sua complexidade e a brevidade do texto proposto, utiliza-se a formalidade matemática já existente como apoio. 
Ao procurar compreender a evolução histórica das tecnologias da comunicação na aprendizagem em Matemática, bem como entender os entraves e as potencialidades dessa interlocução na construção de novos saberes, verifica-se que as TIC nem sempre estiveram presentes nos processos de aprendizagem formal, mas podem ter instigado novos conhecimentos matemáticos desde os primórdios da humanidade. Assim, admite-se que a associação coerente dessas variáveis pode contribuir de forma relevante na construção de saberes no ensino de Matemática na sala de aula.

\section{Saber matemático e aprendizagem incidental}

Muitos alunos veem a Matemática com certo receio, ou mesmo temor, relembrando as experiências escolares ineficazes que já tiveram. Ao que parece, para a maioria dos alunos a Matemática não tem relação alguma com seu cotidiano e muitas vezes o conhecimento prático do cotidiano dessa disciplina parece não ter caráter de saber relevante.

Resultados de pesquisas do Instituto Nacional de Estudos e Pesquisas Educacionais Anísio Teixeira apontam que do percentual de alunos do Ensino Médio avaliados em 2017, somente 4,52\% dos estudantes superaram o nível 7 da Escala de Proficiência em Matemática na Educação Básica brasileira. Tal constatação reforça os estudos de Glória (2003) que indicam que a escola ao consentir com a permanência de discentes por seguidos anos escolares, sem propiciar uma aprendizagem efetiva, outorgando certificados esvaziados de valor social, sem utilidade tanto para prosseguimento de estudos quanto para ingresso no mercado de trabalho, conduz os discentes a uma exclusão perversa.

Carraher, Carraher e Schliemann (1988) e Carretero (2014) sinalizam crianças que vivem ou trabalham nas ruas, sem alfabetização e escolarização regular, demonstram habilidades em resolver certos problemas matemáticos propostos, especialmente aqueles relacionados à gestão de dinheiro e venda de produtos. Mesmo sem a padronização dos alunos escolarizados essas crianças conseguem solucionar situações matemáticas complexas, evidenciando um saber matemático sem os quais não poderiam exercer tais atividades em seu dia a dia. Para Teresa Vergani:

A matemática de uma criança de rua em Angola, a matemática do Movimento dos Sem Terra no Brasil, a matemática urbana vinculada às tecnologias e as mídias, a matemática da aquisição de bens em países em guerra, são exemplos de outras tantas formas de conhecimento matemático vital que se adquirem, em geral, à margem das salas de aula. (VERGANI, 2007, p. 7).

Nesse contexto de reflexões, faz-se necessária uma análise mais profunda sobre aprendizagem incidental, isto é, das oportunidades naturais de construção de novos saberes, situações não-intencionais, surgidas por acidente, devido acontecimentos do cotidiano, observação, interação social, ou como subproduto de uma outra atividade. (ANTONELLO, 2006; WATKINS e MARSICK, 2001).

Nessa perspectiva, Carretero (2014) indica que há uma situação paradoxal que precisa ser repensada. Para ele, crianças que aprendem matemática sem intenção explícita de fazê-lo e mediante aprendizagem incidental têm conseguido resultados significativamente melhores que os alunos que recebem uma 
aprendizagem intencional ${ }^{1}$. Segundo o autor, tal situação acontece porque as atividades propostas aos primeiros aprendizes encontram-se mais conectadas ou mesmo relacionadas de forma mais estreitas com as tendências e comportamentos do indivíduo, e tal ligação permite que a informação recebida e as ações praticadas se convertam em conhecimento útil ao aprendente. Sob esse prisma D'Ambrósio afirma que:

O cotidiano está impregnado dos saberes e fazeres próprios da cultura. A todo instante, os indivíduos estão comprando, classificando, quantificando, medindo, explicando, generalizando, inferindo e, de algum modo, avaliando, usando os instrumentos materiais e intelectuais que são próprios à sua cultura. (D'AMBROSIO, 2013, p. 22).

Logo, aprender matemática nessa concepção é mais que se deter apenas em fórmulas abstratas, refere-se à compreensão da matemática como ciência que instiga a aplicação desses saberes numa realidade viva e consciente.

A posição assumida por autores como Vergani (2007) e D’Ambrósio (2013) pressupõe uma valorização do meio de convívio do aluno, do saber que sua cultura já produziu, não negligenciando suas particularidades, mas atentando-se para seus diálogos e os embates construídos coletivamente. Nessa perspectiva, presume-se uma matemática que instiga a emancipação do indivíduo e não sua doutrinação.

Diante deste cenário faz-se importante destacar e recobrar o pensamento de John Dewey (1978), quando coloca aos educadores que não se pode fazer ensino desvinculado da vivência do aprendente. Suas ideias apontam uma teoria de caráter democrático que valoriza o saber acumulado pela sociedade e a experiência vivenciada pelo sujeito.

Para Dewey (1979b) não há democracia sem educação reflexiva e vice-versa. Logo, ensinar bem é um exercício de projeção social. Nesse viés, não há espaço para uma educação tradicional que proporciona experiências pedagógicas que não estimulem o diálogo com a realidade social. Nesse raciocínio, o autor fez uma série de questionamentos pertinentes até hoje, como:

\begin{abstract}
Quantos estudantes, por exemplo, se tornam insensíveis as ideias, e quantos perdem o ímpeto por aprender, devido ao modo por que experimentam 0 ato de aprender? Quantos adquirem habilidades por meio de exercícios de automatismo e assim limitam a capacidade de julgar e agir inteligentemente em situações novas? Quantos acabam por associar o processo de aprendizagem com algo de enfadonho e tedioso? Quantos acharam o que aprenderam tão alheio às situações da vida fora da escola, que nenhuma capacidade de controle puderam desenvolver para o comando da vida? (DEWEY, 1979a, p. 15).
\end{abstract}

Dessa forma, partindo das capacidades e habilidades que o aluno já possui, a escola deve estimular construção e reconstrução de saberes em novas direções, com base no pensamento reflexivo e esforço inteligente (DEWEY, 1979a, p. 93). Nessa concepção, Dewey compreendia que os alunos aprendiam também de modo informal, isto é, fora da intencionalidade escolar e que essa aprendizagem deveria ser considerada pelo professor. Para ele, as experiências vivenciadas

\footnotetext{
1 Segundo Cipriano Luckesi (2011), para que a aprendizagem seja intencional é necessário que haja também um ensino intencionalmente estabelecido. Logo, essa aprendizagem não depende de ocorrências ocasionais, fortuitas, mas de atividades sistemáticas planejadas previamente pelo educador.
} 
constituem momentos ímpares de aprendizagem que não devem ser abandonadas.

Assim, entendendo a importância dessa construção de saberes informais evidencia-se, nesse artigo, a aprendizagem incidental ou espontânea. Como citado, essa aprendizagem pode ocorrer de formas distintas e diante de variados estímulos podem se encontrar diferentes resultados, entre eles o desenvolvimento de habilidades de reflexão crítica (WATKINS; MARSICK, 2001), a competência melhorada, a mudança de atitudes, o aumento de habilidades interpessoais, o desenvolvimento de autoconfiança, a ampliação de habilidades em geral, além de maior autoconhecimento (ANTONELLO, 2006).

Contudo, para Antonello e Godoy (2011) há uma dificuldade em reconhecer a aprendizagem não-planejada como uma estratégia de aprendizagem, devido esta não ter caráter programado e consciente. Isso porque a intenção primária da atividade é realizar a tarefa ou apresentar uma ideia e não necessariamente aprender. Logo, quando a aprendizagem incidental acontece é uma surpresa, um subproduto de outra ação.

Entretanto, evidencia-se que a indicação de sua efetividade no cotidiano brasileiro reforça a necessidade de análise da aprendizagem espontânea no Ensino de Matemática, bem como a possibilidade de tornar ainda mais efetivos os resultados do ensino ministrado nas classes escolares do nosso país.

\section{Tecnologias de Informação e Comunicação}

Ao longo da história da humanidade, são inúmeras as indicações deixadas pelo homem sobre o uso de ferramentas que lhes auxiliavam em alguma tarefa. Tais ferramentas, que iam de pequenos pedaços de pedra ou pau a um abridor de lata industrializado, e são usados nos dias de hoje, é o que podemos chamar de tecnologia. Perles (2007, p. 4) sobre tecnologia menciona ser "[...] qualquer mecanismo que possibilite ao homem executar suas tarefas fazendo uso de algo exterior ao seu corpo, ou seja, tudo aquilo que se caracteriza como extensão do organismo humano".

Para além de um auxílio físico, a tecnologia se expandiu e tomou novos rumos com o desenvolvimento da informática. A tecnologia passou a ser uma ferramenta indissociável da comunicação e da informação, impactando diretamente na relação social e cultural entre as pessoas. Assim, entende-se que as Tecnologias de Informação e Comunicação (TIC) relacionam-se com mecanismos que possibilitem a informação e comunicação do indivíduo, com caráter intencional de chamar a atenção do leitor, despertando nele interesse por conhecer a informação ou se apropriar da comunicação destinada a ele ou a outros grupos.

Lembra-se, porém, que ao pensar nas TIC, deve-se atentar para não se reportar apenas aos equipamentos tecnológicos da atualidade adotados no dia a dia. É importante ter claro que pensar em tecnologia exige uma reflexão mais ampla, é preciso buscar na memória da história da humanidade as primeiras modificações primitivas no sentido de desenvolver tecnologias e assim comunicar-se com os pares e/ou outros grupos.

Como parâmetro de compreensão e divisão dessas épocas a serem investigadas, utilizam-se as referências de McLuhan (2005) que indicam quatro épocas 
significativas na sociedade, devido fortes influências das tecnologias de comunicação, são elas: a) A cultura tribal, b) A cultura dos manuscritos, c) A galáxia de Gutemberg e d) A era eletrônica.

\section{Cultura Tribal}

Para McLuhan (2005) a tribalização ou a cultura tribal dos povos remete a um período em que a linguagem oral era um instrumento fundamental para a comunicação e a sobrevivência do grupo. Sem domínio da escrita e reunidos em tribos, os ritos e saberes desses povos eram passados de geração a geração por meio da oralidade.

Observa-se que muitos estágios foram superados para que a comunicação humana alcançasse o significado social que hoje possui. Entretanto, autores afirmam que desde a Pré-História o homem já procurava, por meio da comunicação, retratar os acontecimentos de seu dia a dia aos outros.

Assim, buscou-se nas memórias históricas por indicações das primeiras manifestações de tecnologia a serviço da informação e/ou da comunicação, entendendo que estas são aquelas que se propõem a informar ou comunicar uma ideia, um rito, um conhecimento ao outro ou a outros.

Para Silva (2008) os registros rupestres são vestígios da materialização do pensamento simbólico condicionados às experiências culturais do grupo que produziu tal representação, de forma que estudá-los permite a compreensão dos grupos que viviam no Brasil pré-cabralino.

Nesse contexto, Barbosa (2007) em seus estudos sobre grafismos pré-históricos afirma que "[...] o conjunto dos registros rupestres é considerado, na moderna literatura arqueológica, como uma manifestação cultural inclusa no sistema de comunicação, expresso em uma linguagem visual específica" (BARBOSA, 2007, p. 21).

Barbosa (2007) entende que o anseio de comunicar suas memórias a outros grupos é confirmado ao analisar o espaço gráfico de alguns sítios arqueológicos com pinturas rupestres. Tal análise indica que os grafismos dos locais pesquisados estão, normalmente, dispostos nos setores centrais de sítios arqueológicos ou em locais abrigados, como as cavernas:

Todos os espaços grafados encontram-se em locais bastante acessíveis ao olhar de quem chega ao sítio, funcionando como uma espécie de outdoor primitivo; exceto, quando o espaço grafado é o teto. Desta forma, pode-se pensar que havia a intenção dos autores protegerem as pinturas da incidência direta do sol e da chuva; mas, dentro dos setores abrigados, elegiam os locais mais visíveis como o espaço de comunicação. (BARBOSA, 2007, p. 117).

Assim, tais investigações nos indicam que mesmo de forma rudimentar o homem já havia desenvolvido uma tecnologia capaz de comunicar-se com seus pares combinando elementos naturais para suas representações.

Essa evidência reforça-se no vasto repertório existente no território brasileiro. Diversos pesquisadores, especialmente historiadores e antropólogos, têm procurado compreender a representação dos sinais deixados. 
No entanto, algumas pesquisas já indicam que nos registros rupestres há comunicação do pensamento matemático da época. Dentre essas pesquisas citase Magalhães (2011) cujos estudos indicam que alguns registros "[...] parecem estar relacionados com ações de contabilidade, ou como séries regulares", sendo natural que tenham servido a "fins matemáticos" (MAGALHÃES, 2011, p. 205).

Figura 1 - Pontilhados nos sítios Ponta da Serra Negra e Pedra do Urubu
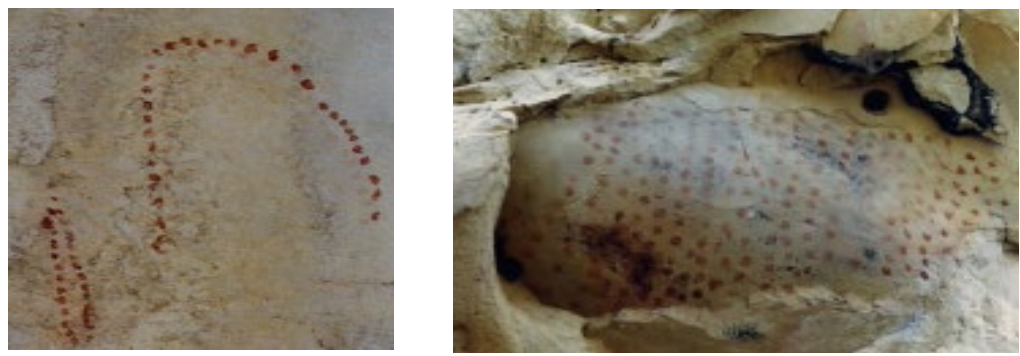

Fonte: MAGALHÃES, 2011, p. 206.

Essa percepção fica evidente na análise dos pontilhados apresentados na Figura 1, como a autora aponta, nos registros deixados parece haver informações sobre análises contábeis que podem ter sido utilizados e descritas nas rochas existentes.

Esse tipo de comunicação, que transcende a célula do indivíduo, alcançando outros grupos, sejam eles de sua época ou de gerações posteriores, também esteve presente nos grupos indígenas da ilha do Marajó no Pará. Sobre isso, Linhares (2015) indica que os marajoaras que viveram no Estado do Pará, na ilha do Marajó, entre 400 a 1.300 a.C., e os vestígios deixados indicam o uso de uma tecnologia e uma complexidade singular na produção de artefatos.

Segundo Amélio (2012) os marajoaras utilizavam a argila como matéria-prima básica, acrescendo a esta, cascalho, ossos e cinzas. Depois de modelar, as peças produzidas seguiam ao forno onde as secavam. Para o acabamento recebiam cores: preto (jenipapo ou carvão mineral), vermelho (urucum) e branco. Registrase que algumas tribos utilizavam verniz, deixando as produções impermeabilizadas.

Braga apud Silva Neto (2014), analisando as produções desses povos, percebeu que:

\footnotetext{
Sem os instrumentos modernos que os auxiliassem na pureza das linhas retas ou curvas, tinham eles a intuição da simetria na divisão geral do objeto, cuja face devia ser decorada, na harmonia não só dos detalhes como do conjunto da ornamentação, do equilíbrio dos assuntos escolhidos, havendo, enfim, uma orientação pré-estudada para a ornamentação de cada objeto a ser decorado. (BRAGA apud SILVA NETO, 2014, p. 97).
}

Destacam-se, dentre tantas produções marajoara, as urnas fúnebres, as quais continham informações registradas no seu exterior, diferenciadas cada uma pela exuberância da decoração. Normalmente, tais manifestações pretendiam comunicar as relações sociais mantidas em vida (SHAAN, 2007).

Além das urnas registra-se também nos adornos plumários, nos cestos trançados, nas máscaras ritualísticas, nas pinturas corporais e em tantos outros objetos a expressão desse saber matemático ainda pouco conhecido e valorizado. 
D’Ambrósio (2001) refere-se à busca de explicações para o conhecimento matemático dessa época e indica essa investigação como a essência do Programa Etnomatemática de pesquisa histórica.

\begin{abstract}
Alguns estudos de etnomatemática procuram enveredar pela história das tradições e permitem fazer algumas suposições sobre a natureza do conhecimento indígena na época da conquista. Por exemplo, resquícios de sistemas de numeração e a riqueza das figuras geométricas que intervém na decoração, são indicadores de uma organização de conhecimentos sobre quantificação, classificação, ordenação e outras categorias que caracterizam o conhecimento matemático. (D'AMBROSIO, 2001, p. 19).
\end{abstract}

Há literatura que aponta para a existência, mesmo que não intencional, de produções indígenas que informavam (e ainda hoje informam) às gerações de sua época e posteriores a identidade de uma personagem e associada a essa comunicação observa-se uma demonstração evidente do conhecimento daquele povo.

Dessa forma, essas representações de intencionalidade informacional, mesmo sem intenção direta, instigavam a compreensão de ideias matemáticas tais como os saberes associados à geometria: simetria, translação, perspectivas, matrizes, dentre outros.

Nesse sentido, torna-se licenciável uma analogia à cultura local sobre as indicações de Gerdes (2010) acerca de suas pesquisas matemáticas relacionadas com a cultura africana, sua compreensão é a de que:

[...] a Matemática é uma atividade universal; é uma atividade pan-cultural e pan-humana. Em todas as culturas o pensamento matemático tem tido lugar, tanto duma maneira espontânea como duma maneira organizada (GERDES, 2010, p. 159).

\title{
Cultura dos manuscritos
}

Apesar da importância dos saberes construídos pelos povos indígenas, D’Ambrósio (2001) salienta que, com a chegada dos portugueses ao Brasil, o conhecimento existente aqui foi profundamente transformado e em alguns casos chegou mesmo a ser extinto.

Nesse contexto, outras tecnologias de informação e comunicação foram inseridas no território brasileiro e passaram agora a representar o pensamento e saber europeu. Logo, como os portugueses dominavam a escrita, era frequente sua utilização nas variadas formas de expressão que aqui chegaram.

Nos primórdios da dominação portuguesa, as navegações figuravam como prática comum, tendo nessa época como uma das primeiras tecnologias da comunicação as cartas produzidas pelos viajantes marítimos. Em suas viagens, os comandantes eram sempre acompanhados de escrivães que informavam sobre a viagem e as características do local.

Bodnar e Hohlfeld (2017) informam sobre essa evidência que:

Os escrivães relatavam tudo o que viam, ouviam e sentiam. Assim, os relatos ganham uma dimensão maior que a informativa, pois sintetizam o olhar dos europeus diante de uma terra descrita como edênica, em vários sentidos, como pela natureza exuberante; pela nudez, liberdade e vida 
coletiva indígena; pelas possibilidades mercantilistas locais (BODNAR; HOHLFELDT, 2017, pp. 297-298).

Dessa forma entende-se que a Carta de Pero Vaz de Caminha configura-se como uma das primeiras manifestações informativas escritas na língua portuguesa no país. Tal como essa, outras narrativas de viagens marítimas eram relatadas com ricos detalhes e muitas além das descrições das novas descobertas, continham informações sobre as aplicações matemáticas dos novos habitantes no Brasil.

Alguns registros dessas narrativas apresentam informações detalhadas sobre a contabilidade da viagem, descrição das despesas e tempo gasto nas incursões. A partir dessas informações podem-se inferir alguns conceitos matemáticos sobre unidades de medidas, números naturais e operações matemáticas, por exemplo.

Conforme indica Ramos (2008) era comum nas viagens marítimas o comandante ter dificuldade em estabelecer com exatidão a posição do navio no mapa. Nessa época, a latitude já podia ser traçada com segurança, entretanto a longitude era um conhecimento ainda desconhecido ${ }^{2}$.

Para Gesteira (2014), das tecnologias utilizadas no período das navegações considerava-se o astrolábio como a mais segura. Este instrumento que tem como função medir ângulos de inclinação dos astros e a posição na Terra era de uso comum aos navegantes. Observa-se que, mesmo sendo uma tecnologia com fins de localização desse período, sua utilização pode instigar o cálculo de alturas e distância de objetos variados a partir do ângulo indicado.

Nesse período, outra tecnologia comum eram os mapas cartográficos que permitiam visualizar dados espaciais, contendo uma riqueza de detalhes geográficos. Reis (2000) afirma que estes recursos pretendiam orientar navegadores e atender as necessidades de militares e colaboradores da colônia. Além disso, até os dias atuais eles oferecem um número amplo de possibilidades de aprendizagens em Matemática, dadas as relações existentes da representação com o espaço real. O leitor, mesmo que não domine a língua escrita, pode a partir do mapa construir conhecimentos, tais como localização e representação espacial. Martinelli (2009) nos indica que:

Os mapas podem mostrar mais do que apenas a posição dos lugares, isto é, fazer mais que responder a questão 'onde?' - papel fundamental da 'base cartográfica' para lastrear as representações temáticas. Eles podem dizer muito sobre os lugares, caracterizando-os. (MARTINELLI, 2009, p. 35).

Dessa forma, percebe-se que mais do que indicações e caracterizações os mapas podem ter instigado a aprendizagem em matemática, evidenciamos a possibilidade de construção de conhecimentos sobre a escala, o fuso horário e a proporcionalidade. Além disso, atualmente, estas tecnologias constituem, a partir de sua observação, manuseio e utilização para localizar referências, lugares ou espaços diversos, em excelentes dispositivos didáticos e interdisciplinares.

\footnotetext{
${ }^{2}$ Naquela época, a determinação do eixo leste-oeste dependia de um relógio que marcasse o tempo que uma barquilha levava para correr pelo casco do navio, fornecendo assim uma estimativa da velocidade média da embarcação e a partir disso, a distância percorrida desde a última marcação realizada. Esse problema foi resolvido apenas no século XVIII com o desenvolvimento do relógio mecânico. Já a determinação do eixo norte-sul era determinada de forma eficiente com uso de astrolábio, balhestilhas e quadrantes, utilizando as estrelas como referência (RAMOS, 2008, p.100).
} 


\section{A Galáxia de Gutemberg e a Revolução da Imprensa}

Um problema que dificultava o acesso de leitores às informações e conhecimentos produzidos no Brasil era a limitação física de um único documento. Deste modo, a imprensa inventada por Gutemberg (1400-1468) surge como oportunidade de expansão das produções escritas. Para McLuhan (2005) uma das características mais importantes da imprensa foi essa possibilidade de replicação das informações permitindo um maior alcance da comunicação.

Para entender a comunicação e intervenção sobre a vida dos indivíduos cita-se Sousa (2006), que discorre sobre a importância do registro da imprensa e sua influência no processo de disseminação da informação no Brasil.

Livros, jornais e revistas transformaram a civilização, pois moldaram a esfera pública moderna, contribuíram para as transformações sociais, políticas e económicas, promoveram a educação e o interesse pelo mundo, fizeram circular ideias e informações, modificaram a cultura. (SOUSA, 2006, p. 138).

A imprensa brasileira, se comparada com o resto do mundo, desenvolveu-se de forma tardia. Conforme Sousa (2006), dos primeiros registros da imprensa mundial até o século XV se utilizava como processo de reprodução a xilografia (arte de gravar em madeira), a maioria recorrentes na China. Entretanto, a partir da década de quarenta, houve uma expansão, ocasionada com a invenção de Gutemberg, a máquina com inúmeros caracteres, conhecida como imprensa de tipos móveis que utilizava metal fundido, sendo esta de extrema importância, pois possibilitava propagar o acesso ao livro, antes privilégio de poucos.

No Brasil, cerca de 350 anos depois, aparecem seus registros precípuos, com o Correio Braziliense em junho de 1808 e a Gazeta do Rio de Janeiro em setembro do mesmo ano. Ainda sobre os jornais publicados, destacava-se em 1825 o Diário de Pernambuco, como "[...] o mais antigo periódico em circulação na América Latina, orientado não para a política, mas sim para o lucro, promovendo as notícias comerciais e a publicação de anúncios" (SOUSA, 2011, p. 17).

O Diário de Pernambuco surgiu, inicialmente, com a intenção de facilitar as transações comerciais da cidade. Entretanto, a partir de suas publicações pode-se instigar a construção de saberes matemáticos em seus escritos ao apresentar o valor do produto, percentual de desconto ao pagar à vista ou a prazo, adotando noções de porcentagem, noções de juros, além de adição, subtração, massa. Conceitos imbuídos incidentalmente.

No mesmo século foram criadas outras duas máquinas de prensa, com a possibilidade de mais jornais circulando no país. Muitos jornais apareceram nos anos seguintes, inclusive voltados para o público feminino, e alguns periódicos destemidos eram editados por mulheres (LIMA, 2009).

Com o crescimento do capitalismo, somado a um quantitativo maior de pessoas alfabetizadas tornando-se potenciais leitores, ganha destaque A Revista Feminina, datada do século XX (1914-1936). Essa publicação era editada por mulheres e com público alvo absolutamente feminino, tendo como objetivo de seus escritos, educar as mulheres para serem boas esposas e mães.

4


Figura 2 - Revista Feminina, n. 145, Junho de 1926.

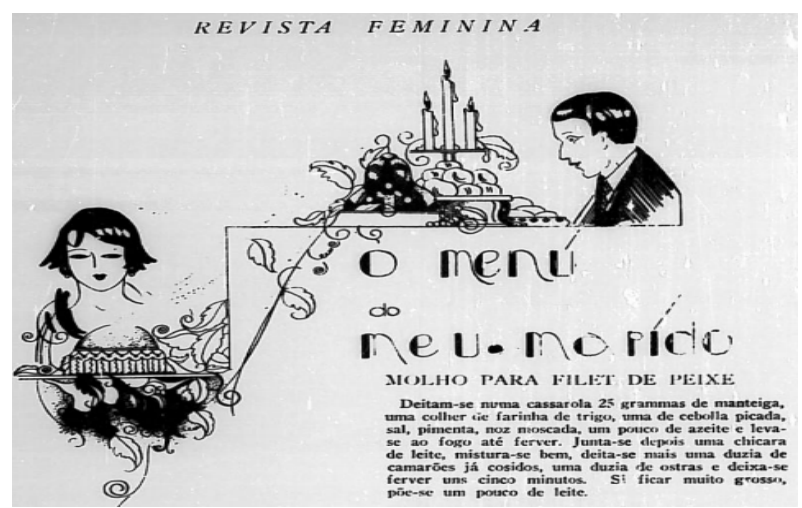

Fonte: https://bibdig.biblioteca.unesp.br/handle/10/6322

Esta imagem é um recorte da publicação da Revista Feminina de 1926, destacando a subserviência da mulher perante a sociedade, tendência esta recorrente em seus exemplares. Outrossim, observa-se que por meio do preparo de receitas culinárias é possível associar a aprendizagem de conteúdos matemáticos, tais como, fração, números decimais, unidades de massa, entre outros.

\section{Era eletrônica e Internet}

Nesse contexto, para McLuhan (2005) merece ênfase a era eletrônica haja vista figurar como período de grandes mudanças nas Tecnologias de Informação e Comunicação. Para ele, nesse período notou-se um rompimento do individualismo e maior participação coletiva a partir das características das tecnologias dessa fase.

Essa mudança de paradigma iniciou-se com a radiodifusão, um serviço de transmissão regular que surgiu em novembro de 1920, nos Estados Unidos. "A palavra rádio é uma apócope de radiodifusão e de radiofonia, [...] por radiodifusão entende-se a transmissão pública de imagens e sons à distância, através de ondas eletromagnéticas" (SOUSA, 2006, p. 571).

No Brasil, sua primeira transmissão é datada de 07 de setembro de 1922, para as cidades de São Paulo, Petrópolis e Niterói, na Exposição Nacional comemorativa do Centenário da Independência Brasileira, sendo um evento no qual se apresentavam as novidades tecnológicas do país (AZEVEDO, 2002). Já a Rádio Sociedade do Rio de Janeiro foi primeira rádio do Brasil, fundada em 1923 por Roquete Pinto e Henrique Morize. Ainda, segundo Azevedo (2002), a radiofonia no Brasil desenvolveu-se de forma lenta, em virtude de seus altos custos de instalação e a baixa frequência no sinal da transmissão, ao passo que até 1930 havia apenas dezesseis emissoras em funcionamento.

L


Comumente, os ouvintes opinavam nas transmissões a serem realizadas e um desses pedidos foi atendido em 1927, quando a Rádio Educadora Paulista transmitiu do Rio de Janeiro para São Paulo uma partida do campeonato brasileiro entre cariocas e paulistas (AZEVEDO, 2002).

Até os dias atuais, essa transmissão é bem acompanhada por muitos torcedores, sendo comum uma minuciosa descrição das partidas. Observa-se que um jogo de futebol narrado pode estimular o ouvinte na concepção de tempo e espaço, pois é informado a todo instante o tempo decorrido da partida, podendo assim inferir diversos conceitos matemáticos, como unidade de medida tempo, modo de apresentá-la através de razão, como por exemplo $1 / 3$ da partida; números ordinais, $1^{\circ}$ e $2^{\circ}$ tempo do jogo; números naturais, quantidades de jogadores; forma geométrica, formato do campo. Tais possibilidades passíveis de serem alcançadas de forma espontânea.

Entre 1945 a 1950 o rádio encontrava-se no auge da chamada "Era de Ouro", tornando-se indispensável nas residências. Miranda (2007) parafraseando Moreira \& Del Bianco (2001), afirma que em 1999, o rádio no Brasil alcançou mais de 40 milhões de domicílios. Mas ao longo de sua história, teve que se reinventar, com a chegada da TV, da internet e logo após, com as redes sociais.

A televisão surge com Francisco Assis Chateaubriand Bandeira de Melo em 1950 que fundou o primeiro canal de TV do país, a Tupi Difusora. Inicialmente, os aparelhos eram importados, e somente em 1951 foram montados os primeiros televisores no país (MIRANDA, 2007). Tornou-se, rapidamente, um meio de comunicação de massa, estando presente em quase todos os domicílios brasileiros.

Um dos programas mais assistido era o do humorista e apresentador Chacrinha. Nele se apresentavam calouros e um corpo de jurado atribuía notas a cada apresentação, a partir dessa informação, mesmo não sendo a finalidade inicial, podem-se extrair conceitos matemáticos. As notas eram somadas, será verificada a diferença da pontuação entre os candidatos, compreensão de ordenação: $1^{\circ}, 2^{\circ}$, $3^{\circ}$ lugar, e ainda a quantidade de músicas apresentadas em cada programa. Tais situações podem ser encontradas nos dias atuais, visto que estes programas são presentes e ainda tem audiência relevante.

Dando continuidade as reflexões sobre a aprendizagem matemática de forma incidental no âmbito das TIC destaca-se o computador. O nome se origina do latim "putare" que significa calcular, portanto, uma amplitude de tecnologia com essa finalidade pode ser considerada um computador, sendo assim, os primeiros registros são datados de 3000 anos a.C. com a criação do ábaco.

Os computadores eletrônicos evoluíram notoriamente ao longo do século $X X$ até chegarem ao que se conhece atualmente. A primeira geração (1940-1959) foi marcada por grandes máquinas que pesavam toneladas. Têm-se, em 1943 Colossos, destinado a elaboração e códigos militares secretos, financiado pelo governo britânico em meio à segunda guerra mundial, orquestrado por Alan Turing. Já Mark I, foi o primeiro computador americano considerado de uso geral, construído pela Universidade de Harvard em 1944 por Howard Aiken. Em 1946, John Mauchly e John Presper Eckest desenvolveram o primeiro computador digital totalmente eletrônico, o ENIAC (Eletronic Numeric Integrator and Calculator) (GABRIEL, 2015). 
Analisando o sistema operacional dessa tecnologia, observa-se que sua linguagem é apresentada em forma de código binário, pois utiliza apenas zeros e uns, sendo Von Leibniz um dos primeiros defensores do sistema binário, a mais de 300 anos. Com tais códigos, pode-se inferir de forma incidental, o estudo de sequências, representação das informações extraídas através de equações, entre outros.

O Brasil adquiriu seu primeiro computador no final da década de 1950, sendo um Univac-120, para calcular o consumo de água da cidade de São Paulo. Em 1972 construiu seu primeiro PC, na USP, o "Patinho Feio", teve esse nome, pois seu projeto inicial era chamado de Cisne Branco, mas seu tamanho era de uma geladeira e a sua memória era comparada a de uma calculadora, por isso patinho feio.

Todo esse processo impulsionou a amplitude do uso do computador no Brasil. Com o passar do tempo, o compartilhamento de informações entre computadores permitiu o desenvolvimento da rede internet. Esta representou uma excelente oportunidade de reunir diversas facetas das TIC existentes em um só ambiente.

O termo internet pode ser compreendido por redes de computadores interligados, globalmente distribuídas (BASTOS, 2000). Surgiu na década de 60, nos Estados Unidos, a priori Arpanet, proposta e desenvolvida a partir de 1963, por Larry Roberts (SOUSA, 2006). Para Sousa (2006, p. 599), as "[...] aplicações como a IRC (Internet Relay Chat) permitiram a comunicação interativa em tempo real. Mas foi a World Wide Web, um sistema que permite a ligação hipertextual de documentos, que revolucionou a rede das redes".

A internet foi disponibilizada para fins comerciais no Brasil em 1995. Com a sua chegada propiciou um avanço nas relações humanas, empresariais e governamentais, disponibilizando acesso em tempo real às informações em dimensões mais amplas, possibilitou a divulgação de som e imagem, forneceu o correio eletrônico, acesso a banco de dados (SOUSA, 2006).

$\mathrm{Na}$ década de 90 , têm-se os primeiros ensaios do que se convencionou chamar de redes sociais, tais como Orkut, criada com finalidade de interação social. Entretanto, devido seu potencial econômico, tais redes receberam maior investimento e passaram a introduzir anúncios durante seu acesso. Assim, Miranda (2007) indica que:

\begin{abstract}
A informação na internet passou a representar um recurso econômico e social em que se percebe ser uma fonte para a satisfação das demandas de informação e serviços, que é facilitada pelo alcance global e potencial, assim como pela redução dos custos dos insumos tecnológicos. (MIRANDA, 2007, p. 34).
\end{abstract}

Em outras palavras, a dinâmica do capitalismo associada ao advento da internet permite uma nova realidade tecnológica. Nesta, surgem plataformas digitais para a criação e desenvolvimento de ferramentas e sistemas no espaço online (internet), o YouTube é uma delas, que tem como objetivo o compartilhamento de vídeos.

Nos dias atuais percebe-se uma proliferação de possibilidades quanto a esse recurso, como por exemplo, os vídeos informativos e de caráter jornalístico, onde o usuário acessa para inteirar-se dos acontecimentos atuais e incidentalmente pode aprender sobre estatística e probabilidade, como subproduto de sua ação. Recorda-se que tal plataforma, fora criada inicialmente para o entretenimento, mas seu uso pode potencializar a aprendizagem matemática.

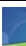


Já atualmente observa-se uma migração digital, onde a internet passa a ser utilizada não apenas em computadores, mas em tablets, notebooks, smart tvs, smartphones. Nesse momento, alguns aplicativos disponíveis favorecem o ensino e a aprendizagem em matemática, apesar da intenção inicial vincular-se ao entretenimento, ao trabalho, à comunicação, sendo assim, um subproduto de sua finalidade inicial.

\section{Considerações}

No atual contexto midiático e retomando a determinados fatos da História da Humanidade, visualiza-se uma relação relevante entre as tecnologias da comunicação e a construção de saberes em Matemática. Desta forma, ao se preocupar em compreender a evolução histórica das TIC e sua estreita vinculação com a aprendizagem em Matemática, fundamentada na perspectiva do conhecimento matemático e na aprendizagem não-intencional, como apresentada neste artigo, possibilitou perceber como o avanço tecnológico propiciou ao ser humano a produção e aprendizagem de novos conhecimentos matemáticos para compreender e interpretar fatos e fenômenos.

O exercício de reflexão sobre as memórias históricas das TIC permitiu, entre outras, compreender algumas das associações possíveis a partir dessas tecnologias e os saberes matemáticos, bem como o desempenho de uma função adicional à sua finalidade precípua, do que é fundamental, para o desenvolvimento sociocultural e científico.

A partir dos registros, como os identificados do Brasil pré-histórico é possível observar que mesmo de forma rudimentar o homem já havia desenvolvido uma tecnologia capaz de comunicar-se com seus pares. Essa comunicação, que já indicava certo pensamento matemático, apontam que as evidências presentes em cavernas e rochas, podem nos dias atuais, sob uma ótica antropológica e, por que não dizer, Etnomatemática, instigar reflexões sobre como eram produzidos os saberes matemáticos, o que pode nos ajudar a compreender a matemática e sua aprendizagem incidental.

Isto é perceptível, no caso dos vestígios deixados pelos povos marajoara, que, como visto, usavam uma tecnologia diferenciada e uma complexidade singular na produção de seus artefatos. Essas representações de intencionalidade informacional, mesmo sem intenção direta, estimularam a compreensão de ideias matemáticas tais como os saberes associados à geometria: simetria, translação, perspectivas, matrizes, dentre outros.

Para além das fronteiras históricas do Brasil, na época das grandes navegações figurava como prática comum as cartas produzidas pelos viajantes marítimos, que aparecem nessa época como uma das primeiras tecnologias da comunicação. Registros nessa forma de narrativas apresentam informações detalhadas sobre a contabilidade da viagem, descrição das despesas e tempo gasto nas incursões, que inferiam em alguns conceitos matemáticos sobre unidades de medidas, números naturais e operações matemáticas, por exemplo.

Salienta-se que, com a revolução da imprensa, jornais e revistas, com a intenção de informar e facilitar as transações comerciais da cidade, passam a publicar escritos que instigavam à construção de saberes matemáticos ao apresentar o

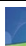


valor do produto, percentual de desconto ao pagar à vista ou a prazo, adotando noções de porcentagem, noções de juros, além de adição, subtração, massa.

$\mathrm{Na}$ era eletrônica, abriu-se um leque para uma quantidade absurda de possibilidades comunicativas, como o rádio, que em pouco tempo se tornou acessível e peça obrigatória e informacional. Como exemplo das possibilidades de aprendizagem em matemática, citou-se o caso de um jogo de futebol que pode estimular o ouvinte na concepção de tempo e espaço, números naturais, quantidades de jogadores; forma geométrica, formato do campo. Tais possibilidades passíveis de serem alcançadas de forma espontânea.

Por outro lado, a televisão apresentava-se com uma gama de possibilidades e, atualmente, observa-se uma migração digital, onde a internet passa a ser utilizada não só em computadores, mas em tablets, notebooks, smart tvs, smartphones, com aplicativos disponíveis que podem favorecer a aprendizagem em matemática, apesar da intenção precípua vincular-se ao entretenimento, ao trabalho, à comunicação, sendo assim, um subproduto de sua finalidade inicial, possibilitando promover uma construção de saberes incidental.

Reconhece-se que, em momentos importantes da História, a tecnologia figura como responsável pelo acesso ao conhecimento, especialmente quando no Brasil tal possibilidade era (é) negada a muitos, seja pela alienação revelada ou pela oculta nos dias atuais. Assim, em cada momento histórico e cada contexto social a acessibilidade e a disponibilidade das TIC permitiram e ainda permitem a uma grande parcela da sociedade a oportunidade de saber, aprender, refletir e construir novos conhecimentos mesmo de forma não planejada.

Dessa forma, entende-se que as TIC estabelecem relações significativas com a construção de novos saberes e na medida em que se dialoga de forma crítica com tais tecnologias pode-se facilitar o ensino e a aprendizagem dos discentes.

Nesse contexto, dentre as oportunidades dessa interação consciente anseia-se pela ressignificação das TIC na sala de aula, tendo em vista o aperfeiçoamento do aprender a aprender e o desenvolvimento da autonomia discente, com um olhar para os construtos históricos e culturais. Assim, a aprendizagem em Matemática, pela essência da disciplina, deve instigar no aprendente uma reflexão crítica e ativa, vislumbrando a utilização consciente dos saberes matemáticos na sociedade que faz parte.

\section{Referências}

ANTONELLO, Claudia Simone. Aprendizagem na Ação Revisitada e sua Relação com a Noção de Competência. Aletheia (ULBRA), v. 26, p. 146-167, 2006. Disponível em: http://repositorio.ispa.pt/bitstream/10400.12/4993/1/COG,\%2012(2),\%20199220.pdf. Acesso em 24 de set. 2018.

ANTONELLO, Claudia Simone; GODOY, Arilda Schmidt. Aprendizagem Organizacional no Brasil. Porto Alegre: Bookman, 2011.

AZEVEDO, Lia Calabre. No tempo do rádio: radiodifusão e cotidiano no Brasil, 1923-1960. 2002. 276 f. Tese (Doutorado). Universidade Federal Fluminense, 
Niterói,

2002.

Disponível

em:

http://rubi.casaruibarbosa.gov.br/bitstream/20.500.11997/643/1/Calabre\%2c\%20L. \%20-\%200\%20r\%C3\%A1dio\%20no\%20Brasil.pdf. Acesso em 24 de set. 2018.

BARBOSA, Ricardo José Neves. As pinturas rupestres da área arqueológica Vale do Catimbau - Buique, Pernambuco: estudo das fronteiras gráficas de passagem. 2007. 177 f. Dissertação (Mestrado). Universidade Federal de Pernambuco. Recife, 2007. Disponível em: https://repositorio.ufpe.br/bitstream/123456789/728/1/arquivo2365_1.pdf. Acesso em: 24 de set. 2018.

BODNAR; Roseli; HOHLFELDT; Antônio Carlos. Brasil em cena: o indígena no contexto do descobrimento e o teatro de evangelização. Revista Humanidades e Inovação v.4, n. 3, p.297-298, 2017. Disponível em: file://C:/Users/New/Downloads/343-1-1923-1-10-20171027.pdf. Acesso em: 24 de set. 2018.

CARRAHER, Terezinha; CARRAHER, David; SCHLIEMANN, Analúcia. Na Vida Dez, Na Escola Zero. São Paulo: Cortez, 1988.

CARRETERO, Mario. Cognição e educação. IN: CASTORINA, José A.; CARRETERO, Mario. (Org.) Desenvolvimento cognitivo e educação. Porto Alegre: Penso, 2014.

D'AMBROSIO, Ubiratan. A matemática na época das grandes navegações e início da colonização. Revista da Brasileira de História da Matemática, vol.1, $\mathrm{n}^{\circ} 1$, 2001; pp.03-20.

D'AMBROSIO, Ubiratan. Etnomatemática: elo entre as tradições e a modernidade. Belo Horizonte: Autêntica, 2013.

DEWEY, John. Democracia e educação: introdução à filosofia da educação. São Paulo: Nacional, 1979a.

DEWEY, John. Experiência e Educação. São Paulo: Companhia Editora Nacional, 1979b.

DEWEY, John. Vida e educação. 10. Ed. São Paulo: Melhoramentos, 1978.

GABRIEL, Ana Paula Camilo. A informática educativa na rede municipal de educação de São Paulo (1994-2013). Dissertação (Mestrado). Pontifícia Universidade Católica De São Paulo, São Paulo, 2015. Disponível em: https://tede2.pucsp.br/handle/handle/10501. Acesso em: 25 de nov. de 2018.

GERDES, Paulus. Da Etnomatemática a arte-design e matrizes cíclicas. Belo Horizonte: Autêntica, 2010.

GESTEIRA, Heloisa Meireles. O astrolábio, o mar e o Império. História, Ciências, Saúde - Manguinhos, Rio de Janeiro, v.21, n.3, jul.- set. 2014, pp. 1011- 1027. Disponível em: http://www.scielo.br/scielo.php?script=sci_arttext\&pid=S0104$59702014000301011 \&$ Ing=en\&nrm=iso. Acesso em 29 de jan. 2020.

GLÓRIA, Dília Maria Andrade. A "escola dos que passam sem saber": a prática da não-retenção escolar na narrativa de alunos e familiares. Revista Brasileira de Educação. Jan/Fev/Mar/Abr 2003. No 22. Disponível em: http://www.scielo.br/pdf/rbedu/n22/n22a07.pdf. Acesso em 27 de set. 2018. 
INEP. Assessoria de Comunicação Social. Saeb 2017 revela que apenas 1,6\% dos estudantes brasileiros do Ensino Médio demonstraram níveis de aprendizagem considerados adequados em Língua Portuguesa. Disponível em:

http://portal.inep.gov.br/artigo/lasset_publisher/B4AQV9zFY7Bv/content/saeb-2017-revela-que-apenas-1-6-dosestudantes-brasileiros-do-ensino-medio-demonstraram-niveis-de-aprendizagemconsiderados-adequados-em-lingua-portug/21206. Acesso em 24 de set. 2018.

LIMA, Sandra Lúcia Lopes. Imprensa feminina, revista feminina. A imprensa feminina no brasil. Projeto História: Revista do Programa de Estudos PósGraduados de História, [S.I.], v. 35, dez. 2009. ISSN 2176-2767. Disponível em: https://revistas.pucsp.br/index.php/revph/article/view/2219/1320. Acesso em: 24 set. 2018.

LINHARES, Anna Maria Alves. Marajoara "civilizado" e identidade nacional brasileira (século XIX). Revista Estudos Amazônicos. vol. XIII, nº 1 (2015).

LUCKESI, Cipriano. Avaliação da aprendizagem escolar: estudos e proposições. 22 ed. São Paulo: Cortez, 2011.

MACLUHAN, Marshall. Os meios de comunicação como extensões do homem. Cultrix: São Paulo, 2005.

MAGALHÃES, Sonia Maria Campelo. A arte rupestre do centro-norte do Piauí: indícios de narrativas icônicas. 2011. 457 f. Tese (Doutorado) - Universidade Federal Fluminense, Niterói, 2011. Disponível em: http://www.historia.uff.br/stricto/teses/Tese-

2011_Sonia_Maria_Campelo_Magalhaes.pdf. Acesso em: 20 de set. 2018.

MARSICK, Victoria; WATKINS, Karen. Informal and Incidental Learning. New directions for adult and continuing education. n. 89, 2001. John Wiley \& Sons.

MARTINELLI, Marcelo. Mapas da Geografia e Cartografia Temática. São Paulo: Contexto, 2009.

MENU do meu marido. Revista Feminina. N. 145, Junho de 1926. Disponível em: https://bibdig.biblioteca.unesp.br/handle/10/6322. Acesso em 24 de set. 2018.

MIRANDA, Gustavo Lima de. A história da evolução da mídia no Brasil e no mundo. 2007. Centro Universitário de Brasil. Disponível em: http://repositorio.uniceub.br/bitstream/123456789/1265/2/20266495.pdf. Acesso em 24 de set. 2018.

PERLES, João Batista. Comunicação: conceitos, fundamentos e história. Mato Grosso do Sul, 2007. Biblioteca on-line de ciências da comunicação. Disponível em: http://www.bocc.ubi.pt/pag/perles-joao-comunicacao-conceitos-fundamentoshistoria.pdf. Acesso em 24 de set. 2018.

RAMOS, Fábio Pestana. Por mares nunca dantes navegados: a aventura dos Descobrimentos. São Paulo: Contexto, 2008.

REIS, Nestor Goulart. Imagens de vilas e cidades no Brasil colonial. São Paulo, Edusp: Imprensa Oficial, FAPESP. 2000.

SCHAAN, Denise Pahl. A arte da cerâmica marajoara: encontros entre o passado e o presente. Habitus. Goiânia, v. 5, n.1, pp. 99-117, jan./jun. 2007. 
SILVA NETO, João Augusto da. Na Seara das cousas indígenas: cerâmica marajoara, arte nacional e representação pictórica do índio no trânsito Belém - Rio de Janeiro (1871-1929). 2014. 145 f. Dissertação (Mestrado). Universidade Federal do Pará, Belém, 2014. Disponível em: http://repositorio.ufpa.br/jspui/bitstream/2011/7212/1/Dissertacao_SearaCousasInd igenas.pdf. Acesso em: 20 de set. 2018.

SILVA, Daniela Cisneiros. Similaridades e diferenças nas pinturas rupestres pré-históricas de contorno aberto no Parque Nacional Serra da Capivara - PI. Tese (Doutorado) - Universidade Federal de Pernambuco. Recife, 2008. Disponível em: https://repositorio.ufpe.br/handle/123456789/396. Acesso em: 20 de set. 2018.

SOUSA, Jorge Pedro. As histórias da imprensa de Nelson Werneck Sodré e de José Manuel Tengarrinha: uma comparação. Biblioteca on-line de ciências da comunicação. 2011. Disponível em: http://www.bocc.ubi.pt/pag/sousa-jorge-ashistorias-da-imprensa-de-nelson-werneck-sodre.pdf. Acesso em: 20 de set. 2018.

SOUSA, Jorge Pedro. Elementos de Teoria e Pesquisa da Comunicação e da Mídia. 2 ed. Porto: Universidade Fernando Pessoa, 2006.

VERGANI, Teresa. Educação etnomatemática: o que é? Natal: Flecha do Tempo, 2007.

Recebido: 02/03/20

Aprovado: $20 / 05 / 20$

Como citar: BATISTA, J. A; SOUZA, A. P.; SOARES, N. N. Da intenção à ação: Relação histórica das tecnologias da informação e comunicação e o ensino da matemática. Revista de Estudos e Pesquisa sobre Ensino Tecnológico (EDUCITEC), v. 6, Edição Especial, e115920, 2020.

Direito autoral: Este artigo está licenciado sob os termos da Licença Creative CommonsAtribuição 4.0 Internacional.

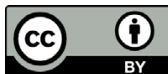

